\title{
Experimental study effect of diameter and number of spray nozzle holes on counterflow cooling tower to improve cooling effectiveness
}

\author{
A'rasy Fahruddin $^{1, *}$, Muslimin Muslimin ${ }^{1}$, Ginanjar Deni Susilo ${ }^{1}$, and Ali Akbar ${ }^{1}$ \\ ${ }^{1}$ Universitas Muhammadiyah Sidoarjo, Faculty of Engineering, Mechanical Engineering Department, Sidoarjo 61215, Indonesia
}

\begin{abstract}
The cooling system is an essential part of the production process within the plant. In the cooling system using cooling tower, efficiency can be improved by increasing the effectiveness of cooling through nozzle modification. This study aims to determine the effect of diameter and number of nozzle holes on cooling effectiveness. The data were taken from the experiments using prototype of counterflow cooling tower with dimension of high x cross-sectional area are $120 \mathrm{~cm}$ x $40 \mathrm{~cm}$ x $40 \mathrm{~cm}$. Diameter varied by $1 ; 1.5$; and $2 \mathrm{~mm}$, while the number of nozzle holes $4 ; 8 ; 16$. The results show that the highest cooling effectiveness was achieved at nozzle diameter $1.5 \mathrm{~mm}$ with the number of holes 8 that is $38.77 \%$.
\end{abstract}

\section{Introduction}

Developments in technology are growing rapidly, industry needs continue to grow, therefore industries need efficient tools to facilitate production activities, especially for industries involved for both thermal power plants and air conditioning industry $[1,2]$. Usually such industries require cooling towers for cooling [3]. Zein et al. [4] recommends that condenser performance can be significantly improved by increasing the diameter of the full conical GCZ nozzle and installing a fine wire on the Cooling Towers (CT) exit display screen. The average condenser pressure is reduced from 0.13 Bara to 0.11 Bara. The average cooling water flow increased by about $3.5 \%$. Furthermore, improved condenser performance increases the average power generation by about 1 to 2 MW in Wayang Windu Geothermal Power Plant, West Java, Indonesia. The cooling tower is a heat exchanger that dissipates the waste heat into the atmosphere to cool the water to a lower temperature [5]. The cooling tower can use a water evaporation process to remove heat and cool the working fluid to near wet bulb ball temperature, whereas in the case of closed-circuit closed cooling towers, rely on air to cool the working fluid to near dry bulb temperature [6, 7]. Mechanical draft cooling towers are the dominant type of cooling tower and many are built in the world. Mechanical draft cooling towers can be forced or induced draft. Air and water flow may be opposite, cross-flow or both [8].

Spray characteristics and droplet size are parameters that are critical in designing spray nozzles to produce an effective spray cooling system. The best spray nozzle has the characteristics of high injection speed, small droplets size distribution, large cone angles and droplet pattern with a uniform droplet size toward the periphery of the spray [3, 9-11]. Spray penetration is significantly influenced by injection pressure. Higher injection pressures result in higher quantity and higher speed droplets. The break-up length characterizes the discontinuity point, where the spray changes from the liquid zone to the small droplet regime. When the liquid exits from the nozzle, the resulting droplet will break smaller into motion into the surrounding gas [12]. Johannes [13] examined the characteristics of cooling towers using several types of pipeline arrangements as liquid distributors. He concluded that cooling tower characteristics (NTU) and heat transfer effectiveness increased with increasing fluid distribution, and decreased with the increase of water/air flow rate. Prabakaran [14] has been researching about effect of diameter of orifice and nozzle on the performance of counter flow vortex tube. Inlet pressure is the main factor for temperature separation. As pressure increases, temperature differences increases in all cases. When the nozzle diameter is small or very large compared to the vortex tube, energy separation affected and resulted in a low cooling effect.

Nozzle spraying results greatly affect the performance of cooling towers. To find out more about the characteristics of the nozzles used in cooling towers, it is necessary to study the nozzle geometry of the cooling tower. The purpose of this study was to determine the effect of diameter and number of nozzle holes on the cooling effectiveness of the cooling tower counterflow.

\section{Experimental method}

Research method using true experimental research that is research done by testing directly. The cooling tower model to be studied is an induced draft counterflow. In

* Corresponding author: arasy.fahruddin@umsida.ac.id 
this research using counterflow cooling tower with pressure: $25 \mathrm{kPa}, 50 \mathrm{kPa}$, and $75 \mathrm{kPa}$, variation of spray nozzle diameter: $1 \mathrm{~mm}, 1.5 \mathrm{~mm}, 2 \mathrm{~mm}$, and variation of number of holes as: 4 pieces, 8 pieces, 12 pieces, and 16 spray nozzle holes. At the time of the study the measured air temperature is $29^{\circ} \mathrm{C}$ and the temperature of the inlet of the cooling tower was maintained at $40^{\circ} \mathrm{C}$.

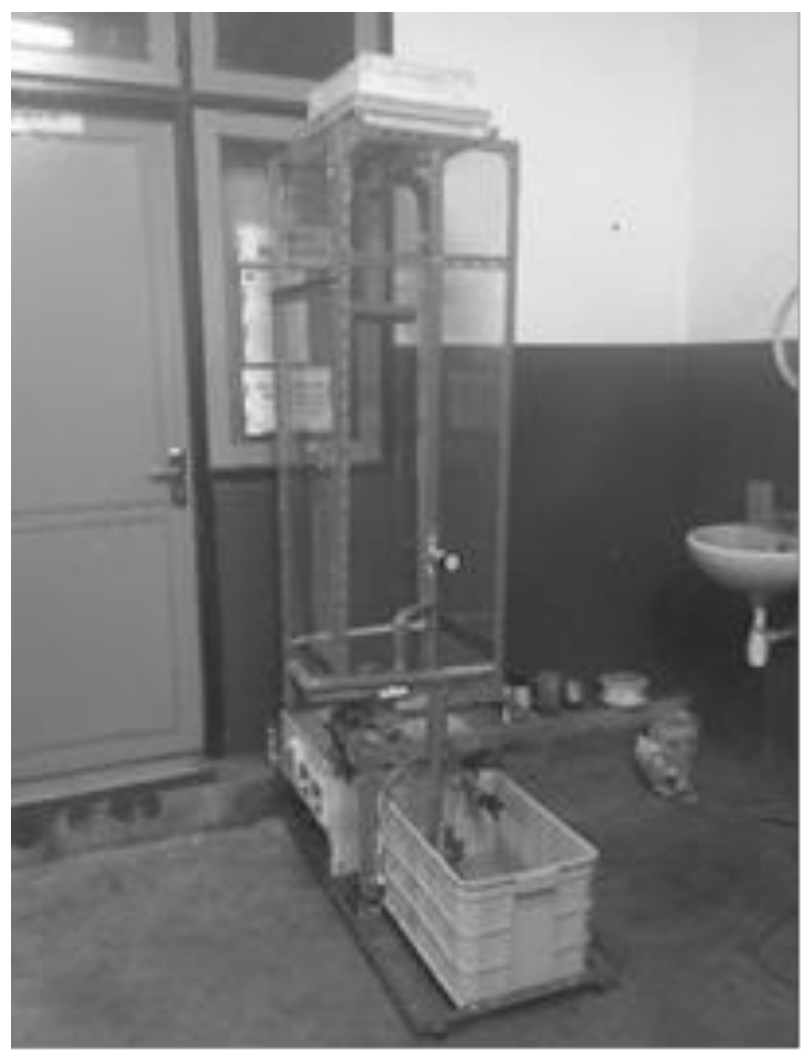

Fig. 1. Prototype of cooling tower testing.

The cooling tower effectiveness is the ratio between the range of the device and the ideal range, where the ideal range is the difference between the cooling inlet temperature and ambient wet bulb temperature. The effectiveness of the cooling tower can be determined by the following formula:

$$
\begin{aligned}
\eta & =\frac{\text { Range }}{\text { RangeIdeal }} \\
\eta & =\frac{\text { Range }}{\text { (Range }+ \text { Approach) }} \\
\eta & =\frac{T \text { in }-T \text { out }}{T \text { in }-T w b} \times 100 \%
\end{aligned}
$$

Where $\eta$ is effectiveness of cooling towers $(\%), \mathrm{T}_{\text {out }}$ is outflow water temperature $\left({ }^{0} \mathrm{C}\right), \mathrm{T}_{\text {in }}=$ Incoming water temperature $\left({ }^{0} \mathrm{C}\right), \mathrm{T}_{\mathrm{wb}}=$ Wet bulb temperature $\left({ }^{0} \mathrm{C}\right)$.

\section{Results and discussion}

\subsection{Variation of diameter to effectiveness}

From the figure 2 it is known that the excellent effectiveness in $\varnothing 1.5 \mathrm{~mm}$ with water pressure $0.75 \mathrm{kPa}$ while for the lowest effectiveness in $\varnothing 1 \mathrm{~mm}$ with water pressure of $0.25 \mathrm{kPa}$. Because the range value on $\varnothing 1.5$ $\mathrm{mm}$ is $5.7{ }^{\circ} \mathrm{C}$ while the approach value is $9{ }^{\circ} \mathrm{C}$. This indicates that smaller nozzle diameters mean smaller diameter droplets [15]. If the diameter is greater, the water resistance will lower, so that the water more spread smoothly and higher dispersion [5]. However, in $\varnothing 2 \mathrm{~mm}$, its effectiveness decreases, it is caused by the water debit is getting bigger so the different temperature of water decreases.

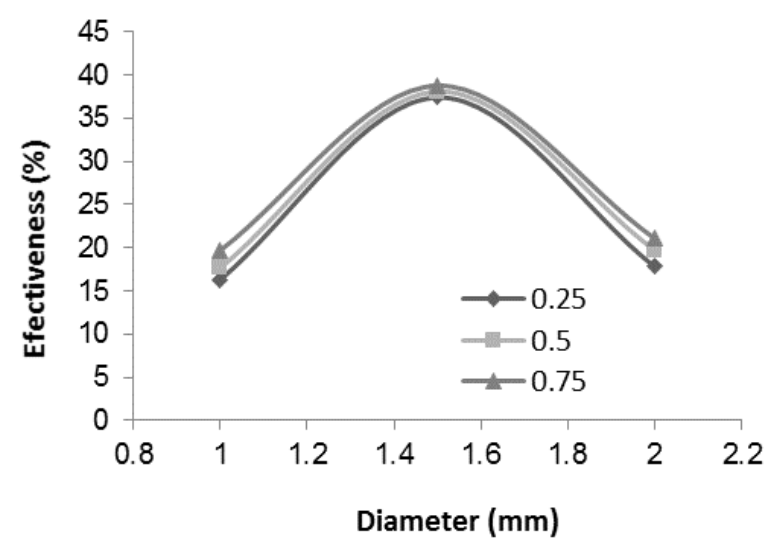

Fig. 2. Variation diameter against effectiveness.

\subsection{Variation of inlet water pressure to effectiveness with different diameter}

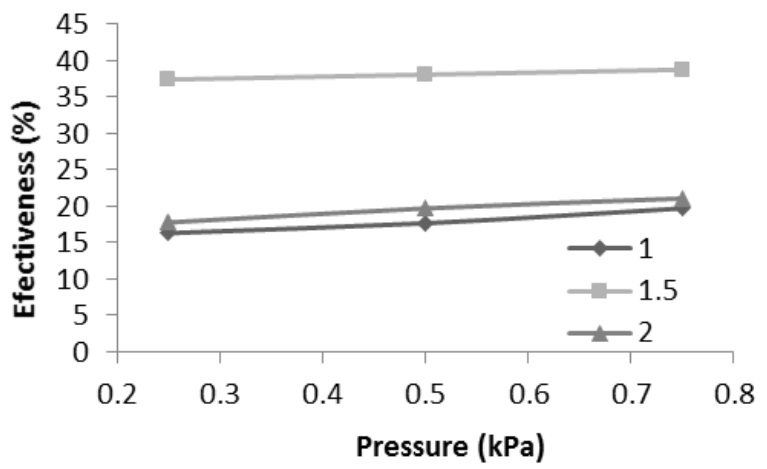

Fig. 3. Variation of water pressure against effectivity at different diameters.

From figure 3 we can see that the increase in pressure does not increase the effectiveness significantly. However, there is still a slight increase. This is because the pressure is higher then the spray will widen. From the figure 3 it is known that the excellent effectiveness in $\varnothing 1.5 \mathrm{~mm}$ with water pressure $0.75 \mathrm{kPa}$ while for the lowest effectiveness in $\varnothing 1 \mathrm{~mm}$ with water pressure 0.25 $\mathrm{kPa}$. 


\subsection{Variation of number of holes to effectiveness}

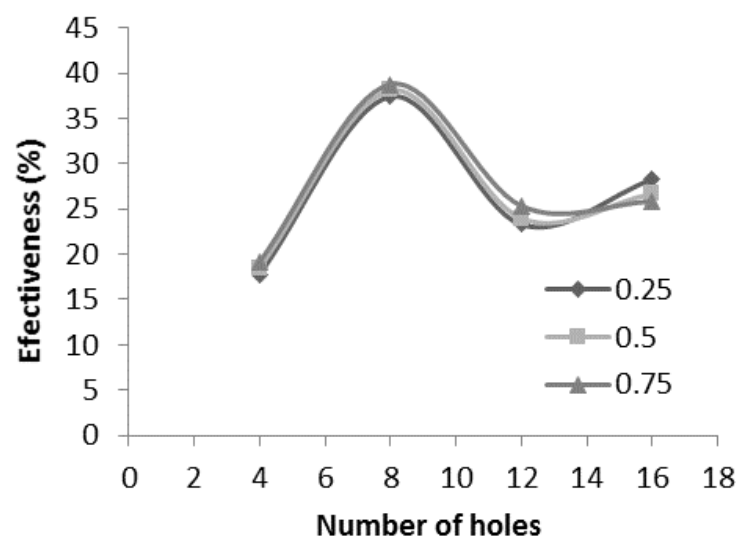

Fig. 4. Variation of the number of holes against effectiveness.

From figure 4, the highest effectiveness at number of holes 8 with the water pressure of $0.75 \mathrm{kPa}$ and the lowest at number of holes 4 with water pressure of 0.25 $\mathrm{kPa}$. Because the range value on the number of holes 8 is very high at $5.7^{\circ} \mathrm{C}$ and the approach is low at $9{ }^{\circ} \mathrm{C}$. This indicates that the number of spray holes more and more heat transfer is more effective because more wide water spray will be more evenly distributed. However, the number of holes 12 trends decreases compared to the number of nozzle holes 8 because if the number of holes is too much then the water discharge is greater even though the water pressure is the same so that the water temperature change will decrease. Weirdness occurs in the trend between the spray hole 12 and the spray hole 16 which slightly increased its effectiveness. This is because more holes the water spray will more wide.

\subsection{Variations of water pressure enter the effectiveness with different number of holes}

From figure 5, it is known that the higher the pressure the higher the effectiveness. This is because the higher the pressure the greater the resulting wide spray. The highest effectiveness value at the number of holes 8 with the water pressure of $0.75 \mathrm{kPa}$ due to high range value and low approach value of $9{ }^{\circ} \mathrm{C}$. Its effectiveness value is the lowest in number of holes 4 with water pressure of $0.25 \mathrm{kPa}$ because of its high approach of $12^{\circ} \mathrm{C}$. However, strangeness occurs in the number of holes 12 where the trend decreases.

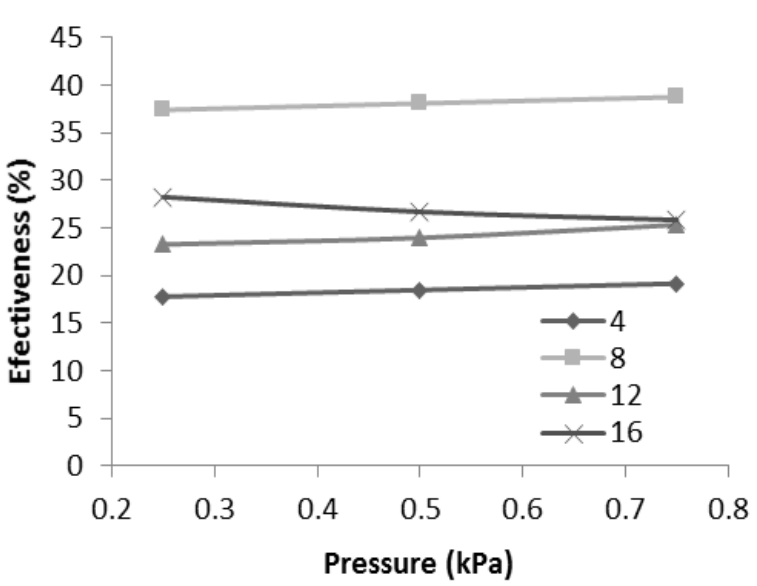

Fig. 5. Variation of water pressure against effectiveness at different number of holes.

\section{Conclusions}

The larger the diameter, the higher the effectiveness of the cooling tower to a certain value, then the effectiveness will decline for the rest. Similarly to the number of nozzle holes, the more the number of nozzle holes, the higher the heat transfer effectiveness to a certain value, and then the effectiveness will decline for the rest. On the small number of holes the water will be inhibited, but when the nozzle hole is too much then the flow will be faster so it will reduce the spray width. From result of research known that best cooling effectivity value equal to $38,77 \%$ at diameter $1,5 \mathrm{~mm}$, number of nozzle hole 8 , and pressure $0,75 \mathrm{kPa}$.

We acknowledged P3I Universitas Muhammadiyah Sidoarjo which facilitated the publication of this research.

\section{References}

1. Y. Sun, Z. Guan, H. Gurgenci, X. Li, K.A. Hooman, "Study on multi-nozzle arrangement for spray cooling system in natural draft dry cooling tower," Appl. Therm. Eng. 124, 795-814 (2017)

2. M.M. Patil, S.J. Patil, P.S. Patil, S.J. Mehta, “Design and Analysis of Cooling Tower," Int. Res. J. Eng. Technol. 5, 2240-2245 (2018)

3. P. Vitkovic, "Influence of a Nozzle Type on the Thermal Performance of the Fill," in Proceedings of the 3rd World Congress on Mechanical, Chemical, and Material Engineering (MCM'17) (2017)

4. A. Zein, A. et al. "Modification of Condenser Nozzle and Cooling Tower Exit Screen to Increase Condenser Performance," Proceedings World Geothermal Congress 25-29 (2010)

5. A. Alkhedhair, Z. Guan, H. Gurgenci, I. Jahn, S. He, "Experimental study on inlet air cooling by water spray for natural draft dry cooling towers enhancement," Proc. 19th Australas. Fluid Mech. Conf. (2014) 
6. R. Sattanathan, "Experimental Analysis on Performance of a Counter Flow Tray Type Cooling Tower,” Int. J. Sci. Res. 4, 1402-1408 (2015)

7. K.J. Dileep, D.K. Baniya, A.C. Kurup, A. Varghese, "Design and fabrication of crack-junctions," Int. J. Latest Eng. Res. Appl. 2, 27-37 (2017)

8. S. Tiwari, “Analysis of Counter Flow Induced Draft Cooling Tower using Taguchi Method," Int. J. Eng. Res. Technol. 4, 292-298 (2015)

9. S.C. Kranc, "Optimal spray patterns for counterflow cooling towers with structured packing," Appl. Math. Model. 31, 676-686 (2007)

10. Z. Guofang, Z. Yuan, C. Qian, "Water distribution below a single spray nozzle in a natural draft wet cooling tower," The 14th IFToMM World Congress, Taipei, Taiwan (2015)

11. A. Alkhedhair, I. Jahn, H. Gurgenci, Z. Guan, S. He, "Parametric study on spray cooling system for optimising nozzle design with pre-cooling application in natural draft dry cooling towers," Int. J. Therm. Sci. 104, 448-460 (2016)

12. A.R. Andsaler, A. Khalid, N.S.A. Abdullah, A. Sapit, N. Jaat, "The effect of nozzle diameter, injection pressure and ambient temperature on spray characteristics in diesel engine," in IOP Conferences Series: Journal of Physics 822, 012039 (2017)

13. S. Johanes, "Komparasi karakteristik menara pendingin menggunakan beberapa tipe susunan pipa-pipa sebagai pendistribusi cairan," Forum Tek. 34, 67-75 (2011)

14. J. Prabakaran, S. Vaidyanathan, "Effect of diameter of orifice and nozzle on the performance of counter flow vortex tube,” Int. J. Eng. Sci. Technol. 2, 704707 (2010)

15. Z. Zhang, C. Zhao, Z. Xie, F. Zhang, Z. Zhao, "Study on the effect of the nozzle diameter and swirl ratio on the combustion process for an opposedpiston two-stroke diesel engine," Energy Procedia 61, 542-546 (2014) 